\title{
Band Saw Blade Crack before and after Comparison and Analysis of Experiments (2)
}

\author{
Jin-gui Gao, Zhao-fang Jiang, Jian Zhang, Hui Li and De-jun Shen and Hong-gang Zhao \\ Beihua University, Jilin, Jilin 132013, P.R.China
}

\begin{abstract}
Based on MJ3310 woodworking band saw machine as the research object, under the no-load and load of Vib system vibration signal acquisition, processing and analysis software of band saw blade transverse vibration test and the signal acquisition and analysis of the collected signals obtained: to determine the transverse vibration displacement $5.66 \mu \mathrm{m} \sim 7.86 \mu \mathrm{m}$ and the main vibration frequency between $624 \mathrm{~Hz} \sim 792 \mathrm{~Hz}$, then saw blade crack at least $3 \mathrm{~mm}$, need timely saw blade, cutting high hardness of wood band saw blade transverse vibration displacement and frequency will increase sharply. Can be generated according to the band saw blade crack before and after the changing rule of the horizontal vibration displacement and frequency of transverse vibration and scope, judgment and replacement time of saw blade saw blade defect types, which can fully rational utilization of saw blade work effectively.
\end{abstract}

\section{Introduction}

In order to eliminate or reduce safety accidents, improve labor productivity, improve the quality of band saw machine for processing, it is necessary for band saw blade falls from the teeth of the reasons and rules, forecast and prevention measures, work safety evaluation of multiple system research. The study of fallen tooth formation has the most overall and basic, it is the study of band saw blade is foundation of work safety, but also to build the core content of safety theory of band saw machine [1]-[3].

Therefore, this paper intends to band saw blade tooth loss were studied and summarized its cause, and changes to the rules, and deeply understanding out the intrinsic relationship between the teeth of each factor, and blade breakage mechanism, for improving the quality of sawn timber processing, the protection of the ecological environment, and prevent safety accident occurrence, reduce safety accident frequency and damage, ensure the safety of the lives and property of the people, have a very important practical significance [4]-[8].

\section{Experimental}

\subsection{Laboratory instruments and equipment}

\subsubsection{Laboratory instruments}

The following experimental instrument: Use of equipment and instruments are as follows: Data acquisition instrument
WS-5942-2-50 Spectrum of Beijing century science and technology Development limited Woodworking band saw machine MJ3310 Foshan new woodworking machinery equipment company.

Instruments used in the experiment connection diagram is shown in Fig. 1.

\subsubsection{Equipment}

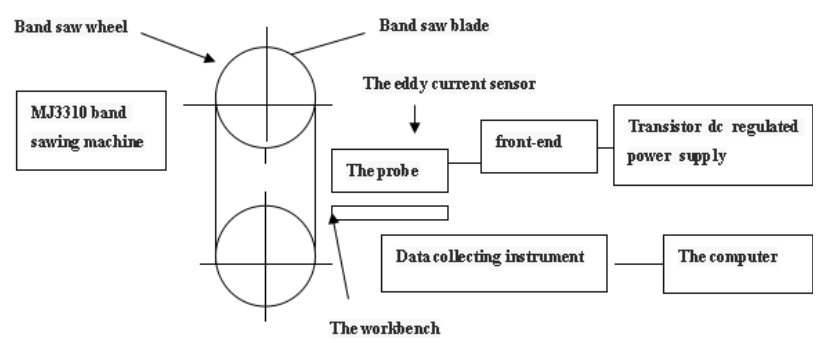

Figure 1. The main instruments and equipment connection diagram

\subsection{Device and its parameter}

\subsubsection{Machine composition}

The experimental research of forestry college at the BEIHUA University of woodworking machinery laboratory MJ3310 cars woodworking band saw. Its structure by saw wheel up and down, band saw blade, guide, tensioning system, power system, frame, security cover and other components. As shown in Fig. 2. 


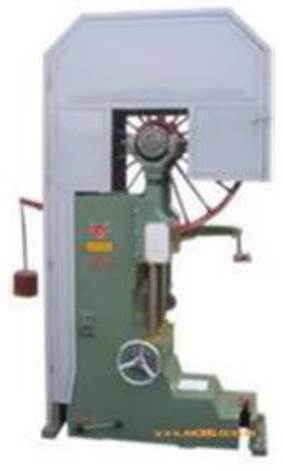

Figure 2. Wood working band saw machine

\subsubsection{Machine parameters}

Equipment: Fine woodworking band saw machine Type: MJ3310 Saw blade diameter: $1000 \mathrm{~mm}$ Saw blade wheel speed: 650rpm Motor speed: 1400rpm Saw blade parameter: $7200 \mathrm{~mm} \times 120 \mathrm{~mm} \times 1.12 \mathrm{~mm}$ (length $\mathrm{x}$ width $\mathrm{x}$ thickness GB/T 21690-2008 Fine woodworking band saw blade dimensions)

\section{Results and discussion}

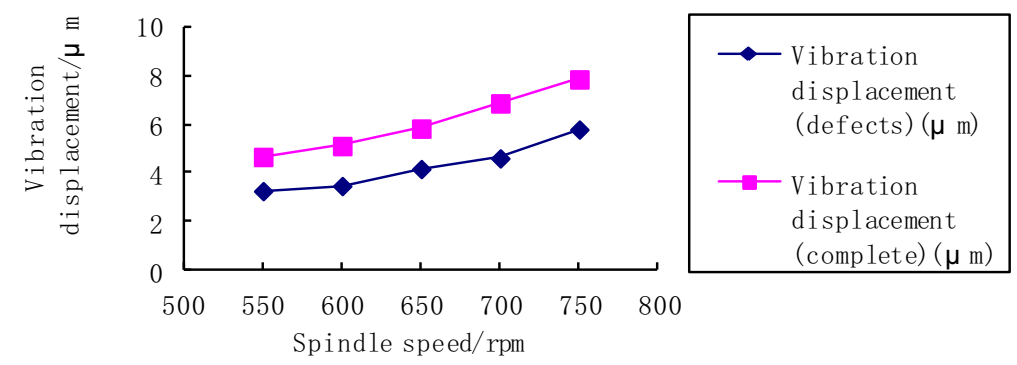

Figure 3. Different saw when complete blade wheel spindle speed and blade transverse vibration displacement of tooth defect

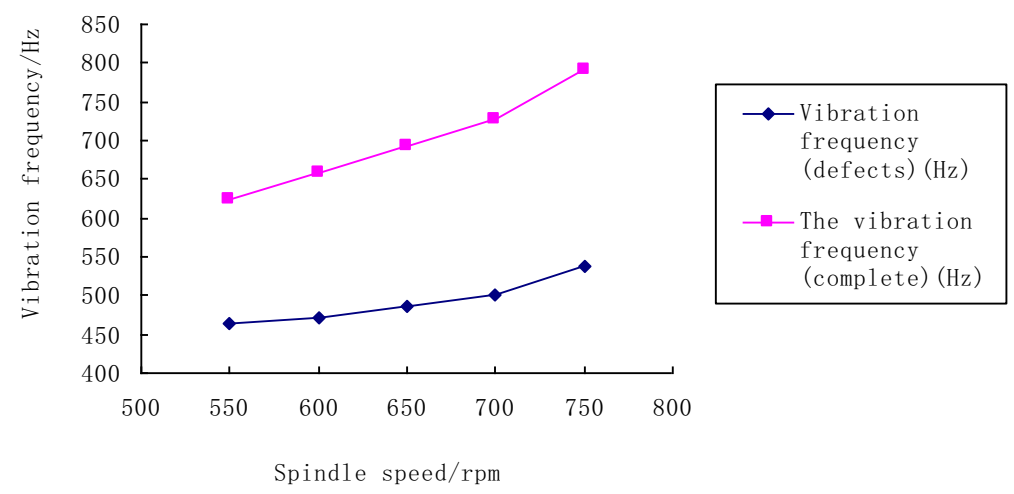

Figure 4. Sindle speed impact on the normal and defect of saw blade transverse vibration displacement

The Fig. 3 shows that,also saw, wheel spindle speed impact on the size of the band saw blade transverse vibration displacement is very obvious, which saw wheel spindle speed is $831 \mathrm{rpm}$ the horizontal vibration displacement minimum, to achieve the best condition, and the other saw wheel spindle speed corresponds to the horizontal vibration displacement increases apparently. When band sawing machine saw wheel spindle speed is

\subsection{Influence of wheel spindle speed of saw blade vibration falling tooth defect}

In the band saw blade tension is $142 \mathrm{~N}$, under the premise of belt tensioning force is $1435 \mathrm{~N}$, use of custom level 3 cone and the original belt pulley, adjusting the five speed, respectively on the full blade and two tooth defect of the saw blade for data acquisition, will now and with the increase of saw wheel spindle speed saw blade transverse vibration displacement collected data into curve as shown in Fig. 3. And will collect the data after the power spectrum analysis, get the frequency data after finishing drawing into curve as shown in Fig. 4. 
observation curve, shown in Fig. 4 will find in the band sawing machine high speed (greater than $700 \mathrm{rpm}$ ), drop tooth vibration main frequency band saw blade, almost no change in speed, both are the obvious contrast, produce tooth defect of band saw blade vibration main frequency will be lower than the whole band saw blade of about $50 \mathrm{~Hz}$. The drop tooth saw blade vibration main frequency between $624 \mathrm{~Hz}$ and $792 \mathrm{~Hz}$.

\subsection{The influence of different tree species of band saw blade transverse vibration cutting}

Blade in different kinds of wood with the case, we will collect the data of transverse vibration of band saw blade. When sawing, in determining the speed of the spindle 650 rpm, band saw blade for the integrity of the state and the band saw blade with $3 \mathrm{~mm}$ crack state, band saw blade tensioning force $1435 \mathrm{~N}$, speed and feed for $15 \mathrm{~m} / \mathrm{min}$, in belt tension tension on the premise of, respectively, the choice of the cutting of Larch and color wood, respectively, after whole band saw blade and crack of the band saw blade cutting data collection and complex analysis, under different conditions with saw blade lateral vibration displacement and vibration frequency of the data as shown in Table 1 .

Table 1. Cutting blade transverse vibration displacement and main frequency contrast different tree species

\begin{tabular}{ccccc}
\hline Tree species & $\begin{array}{c}\text { Larch } \\
(\mu \mathrm{m})\end{array}$ & $\begin{array}{c}\text { Color wood } \\
(\mu \mathrm{m})\end{array}$ & $\begin{array}{c}\text { Larch } \\
(\mathrm{Hz})\end{array}$ & $\begin{array}{c}\text { Color wood } \\
(\mathrm{Hz})\end{array}$ \\
\hline $\begin{array}{c}\text { Have a crack defects of band saw blade } \\
\text { transverse vibration displacement and main } \\
\text { frequency }\end{array}$ & 5.82 & 7.97 & 770 & 880 \\
$\begin{array}{c}\text { Complete blade vibration displacement main } \\
\text { frequency }\end{array}$ & 4.55 & 5.45 & 550 & 650 \\
\hline
\end{tabular}

By Table 1 comparative analysis, we can know that, when sawing, the vibration displacement of the larch wood less than maple, which is due to saw wood hardness, no load is so. The increase of Larch bandsaw blade vibration displacement vibration displacement of the 1 . The vibration displacement of transverse vibration displacement defects cutting band saw blade was significantly higher than that of no-load. From the frequency of the main value analysis and comparison shows that, the vibration frequency of the larch is higher than the color of wood cutting saw blade vibration frequency, which is due to an increase in the hardness of cutting wood, to increase the frequency of vibration; blade vibration frequency of the load is greater than that of empty vector of saw blade vibration frequency. In sawing process, when the vibration displacement of the rigid contact with the blade is larger.

\section{Conclusions}

Through the above type of MJ3310 sports car woodworking band saw band saw blade vibration analysis,

(1) using a $120 \mathrm{~mm}$ wide band saw blade, the impact of band saw blade vibration displacement and vibration frequency of the main factors are: saw wheel spindle speed, the blade tension, feed speed

(2) if the band saw blade vibration displacement between $5.66 \mu \mathrm{m} \sim 7.86 \mu \mathrm{m}$ and vibration frequency between $624 \mathrm{~Hz} \sim 792 \mathrm{~Hz}$, band saw blade at least $3 \mathrm{~mm}$ crack defects, need to replace the band saw blade in time;

(3) cutting high hardness of wood can make the band saw blade transverse vibration displacement and frequency has increased dramatically, has the obvious difference compared with the perfect blade when idle, can according to the band saw blade transverse vibration displacement and frequency range of judging defect types and development degree, thus, can replace the saw blade scientifically, effectively use band saw blade.

\section{Funding for the subject project}

This topic by the Chinese national natural science fund project funding, its national fund name: based on the analysis of time series of woodworking band saw blade tooth crack and damage formation mechanism and prediction theory (31570556).

\section{References}

1. Guo-xi Zhu, Hua-bin Wang et al, Research on the production line of Chinese modern material production line. Harbin, Northeast Forestry University press, September, pp. 2-10, (1989)

2. Jin-gui Gao, Jian-guo Yu, Guo-xi Zhu, Xiao-min, Lai, Jian-hua Dou, The elastic dynamics analysis of band saw Tightening system. Journal of Forestry Research. 11,pp. 27-32 (2000)

3. Jin-gui Gao, Band sawing machines for mechanical computer simulation and experimental study of tensioning system [dissertation], Northeast Forestry University. Library (2001)

4. Fuzhou Woodworking Machine Tool Research Institute, A foreign woodworking machine tool machinery industry basic situation. Beijing: Mechanical Industry Press, (1989)

5. $[\mathrm{Su}]$ Xie Lev, Effect of technical state of Des sawing machine for cutting process dynamics. (Translated) woodworking machine, 4, pp. 8-42, (1989) 
6. Zhang Tieling, The band saw blade tensioning force influence on the stability of the saw blade experimental research dissertation. Northeast Forestry University Library, (1988)

7. Wang Huabin, The band saw blade saw hanging position effect of stress distribution and stability of wood industry of blade width, 4, pp. 5-11, (1989)
8. $\mathrm{Pu}$ Yongshou is in wood cutting. Fukui. At resistance in the analysis of the tool (first report), Journal of wood, 5, pp. 46-51, (1984) 